\title{
PERCENTAGE YIELD OF VOLATILE OIL FROM WOOD DUST OF TREES FROM SAW MILL IN HIMALAYAN AREAS
}

\author{
HEMRAJ VASHIST*, DIKSHA SHARMA
}

Department of Pharmacy, L. R. Institute of Pharmacy, Solan - 173 223, Himachal Pradesh, India. Email: Shimla_pharmacy@rediff.com Received: 10 October 2016, Revised and Accepted: 19 December 2016

\begin{abstract}
Objective: Trees with medicinal values have always been ignored and neglected from their inherent medicinal value. Instead of their medicinal use, such plants are widely used by carpenters and also by people for cooking. The irrational uses of such valuable flora are diminishing our medicinal plants' bank. There is no doubt that the uses of such plants by carpenters are a necessity of growing society. Then, we need to opt any other middle way to fulfill both the necessities from such valuable flora. By considering this, all the present study is focused on the extraction of volatile oil from sawdust of Pinus roxburghii and Cedrela toona (SDPR and SDCT) was carried out in the present study.
\end{abstract}

Methods: Here, in the present work, we have collected the fresh powder near from the running saw of working carpenter cutting Pinus roxburghii wood and Cedrela toona wood into flat board. The SDPR and SDCT were then weighed and filled separately to two 500 ml round bottom flask, and clevenger apparatus assemblies were adjusted for both. The temperature was adjusted at $75^{\circ} \mathrm{C}$. Hydrodistillation was continued for 3 hrs.

Result: The result revealed $0.5 \% \mathrm{v} / \mathrm{w}$ of volatile oil from SDPR in 3 hrs. The meniscus observed for SDCT is slightly blurred up to $0.5 \mathrm{ml}$ ( 2 mm) which was considered as volatile oil. The total percentage so obtained was calculated as $0.25 \% \mathrm{v} / \mathrm{w}$.

Conclusion: The present study may guide to utilize the saw rust from pine and red cedar plant to isolate valuable medicinal constituents. Further, the study may help the researcher to use wood dust to research different ways.

Keywords: Pinus roxburghii, Cedrela toona, Hydrodistillation, Herbal medicine.

(C) 2017 The Authors. Published by Innovare Academic Sciences Pvt Ltd. This is an open access article under the CC BY license (http://creativecommons. org/licenses/by/4. 0/) DOI: http://dx.doi.org/10.22159/ajpcr.2017.v10i3.15611

\section{INTRODUCTION}

Cedrela toona Roxb. (Meliaceae) is nearly evergreen tree growing at a height up to $18 \mathrm{~m}$ and distributed tropical Himalayas from the Indus eastward, ascending to $1000 \mathrm{~m}$ and also hills of central and southern India [1]. The plant is used in the form of decoction as "Daha," Gandhmala, Kandu, Kustha, Prameha, Raktapita, Raktvikar, Visavikara, Varna, Yoniroga, Bala pravahika, Svetakustha, medovikara in the dose of 3-6 g decoction in 10-20 ml [1]. The plant is also known as red "cedar." Toona ciliate and Toona sinensis are another botanical name for the plant. Two novel Limonoids, namely, cedrelone and 23-hydroxy toonacilide, have been isolated from the plant [2]. Sesquiterpenoids, triterpenoids, limonoids, and flavonoids of Chromolaena odorata graft and speculations on the induced resistance against Hypsipyla grandella have been reported [3]. Each part of Pinus roxburghii (Pinaceae) is a subject of the folklore and mythology of indigenous culture in several Himalayan regions. The volatile oil from different parts of the plants of the pines tree has been reported to show antibacterial activities against Gram +ve and -ve bacteria [4]. P. roxburghii oil has been traditionally used to treat cuts, boils, blisters, and wounds. In addition, phytochemical screening of pinus tree stem has been primarily used as a source of turpentine oil while needles and stems have found abundant amounts of vitamin C, tannins, and alkaloids [4]. The major constituent of the pinus tree has been reported as cellulose. It has also been found that the area where the inert char of pinus tree stays and shows very less microbial proliferation [5].

\section{METHODS}

Wood dust of SDPR and SDCT was collected from the saw mill from Gharsi village hills of Himachal, India. Total $20 \mathrm{~g}$ (Fig. 1a and b) of dust was weighed and then added to two $500 \mathrm{ml}$ round bottom flask separately.
The clevenger apparatus assembly was adjusted. The distillation was continued for $3 \mathrm{hrs}$ at $75^{\circ} \mathrm{C}$ (Fig. 1c) [6-8]. An experimental result has already been reported as microwave-assisted extraction-headspacesolid phase microextraction followed by gas chromatography-mass spectrometry (GC-MS) is a simple, time-saving, and solvent-free method, and it is a potential analytic tool for the determination of the volatile compounds from T. sinensis [9].

\section{RESULT AND DISCUSSION}

In the present work, $0.5 \% \mathrm{v} / \mathrm{w}$ was obtained in case of SDPR after $3 \mathrm{hrs}$ (Fig.1d and e) while $0.2 \mathrm{ml} \mathrm{v} / \mathrm{w}$ was reported in case of SDCT in the same time (Fig.1 f). The chemical components of essential oil of T. sinensis leaf blades and their petioles from China were extracted by simultaneous distillation solvent extraction and were analyzed by GC-MS. The main components of essential oils were reported as sesquiterpene and sesquiterpene oxygenated compounds, accounting for $90.1 \%, 92.6 \%$, and $80.9 \%$ of the relative mass fraction, respectively [10]. In case of P. roxburghii, GC-MS analysis for the cone oil has been reported to have 81 compounds with 78 components being identified ( $95.5 \%$ of the oil) while $98.3 \%$ of needle oil was identified to contain 68 components and $98.6 \%$ of the bark oil (38 components) was identified [4].

\section{CONCLUSION}

As for both tuna and pines trees, several remarkable pharmacological properties on their volatile oil have been reported by several researchers; the present work is an attempt to show the use of the waste sawdust of pines and tuna trees for the extraction of volatile oil. Moreover, the volatile oil so obtained may be used by researchers to work further. In this way, the wastage of such valuable plants can be minimized. The wastage as sawdust may also be utilized. 


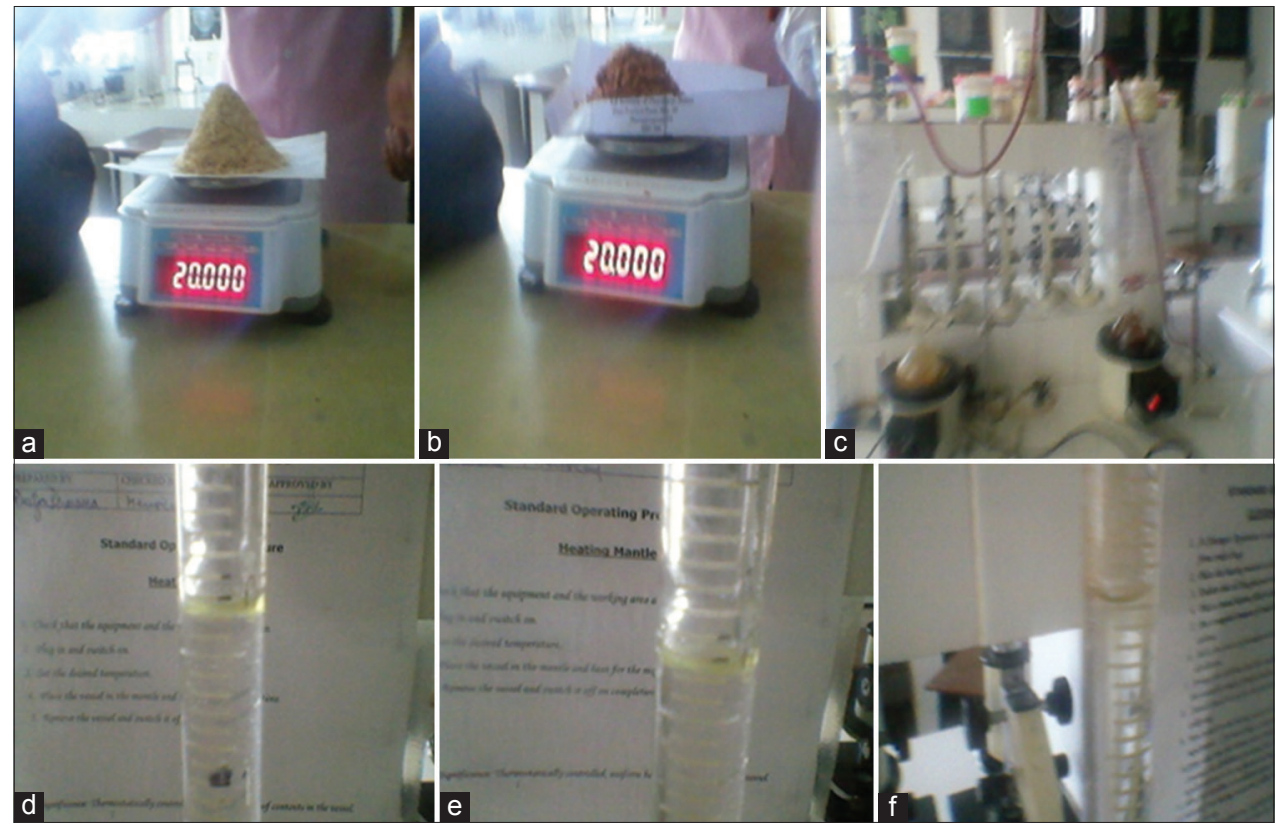

Fig. 1: Different aspects of experiments performed on sawdust of Pinus roxburghii (SRPR) and sawdust of Cedrela toona (SDCT).

(a and b) Weighing of SRPR (left) and SDCT (right) up to $20 \mathrm{~g}$, (c) Hydrodistillation assembly for SDPR (left) and SRCT (right),

( $d$ and e) level of SDPR extracted volatile oil collected above the water level, (f) level of extracted volatile oil of SDCT above the water level

\section{REFERENCES}

1. Government of India, Ministry of Health and Family Welfare, Department of Ayurveda, Yoga \& Naturopathy, Unani, Siddha and Homoeopathy (AYUSH). Ayurvedic Pharmacopoeia of India. Part 1. Vol. 5. 1989. p. 210-1.

2. Hu J, Song Y, Mao X, Wang ZJ, Zhao QJ. Limonoids isolated from Toona sinensis and their radical scavenging, anti-inflammatory and cytotoxic activities. J Funct Foods 2016;20:1

3. Paula JR, Vieira JC, Silva FD, Fo ER, Fernandes JB, Vieira PC, et al. Sesquiterpenes triterpenoids, limonoids and flavonoids of Cedrela odorata graft and speculations on the induced resistance against Hypsipyla grandella. Phytochemistry 1997;44:1449-54.

4. Satyal P, Paudel P, Raut J, Deo A, Dosoky NS, Setzer WN. Volatile constituents of Pinus roxburghii from Nepal. Pharmacognosy Res 2013;5:43-8.

5. Baldock JA, Smernic RJ. Chemical composition and bioavailability of thermally altered Pinus resinosa (Red pine) wood. Org Geochem
2002;33(9):1093-109.

6. Vashist H, Sharma D. A report on percentage yields of calcium citrate from citrus fruits and hydrodistillation of dried orange peel and cinnamon bark powder. Int J Pharm Pharm Sci 2013;5(1):401-3.

7. Vashist H, Rathore DS, Singh G. A Comparative report on the percentage yield of volatile oil from citrus fruits by hydrodistillation. Singapore J Sci Res 2014;4:15-8.

8. Sharma D, Vashist H. Hydrodistillation and comparative report of percentage yield on leaves and fruit peels from different citrus plants of Rutaceae family. J Plant Sci 2015;10(2):75-8.

9. Ruimin M, Wang X, Liu S, Yuan X, Wang S, Fan Z. Rapid determination of volatile compounds in Toona sinensis (A. Juss.) Roem. by MAE-HSSPME Followed by GC-MS. Chromatographia 2007;65:463-7.

10. Chen C, Tong Z, Liao D, Yue L, Yang G, Mingfei L. Chemical composition and antimicrobial and DPPH scavenging activity of essential oils of Toona sinensis (A. Juss.) Roem from China. BioResources 2014;9(3). 